\title{
Safety and Security Needs of the Aging People in Tehran, Iran
}

ISSN: 2578-0093

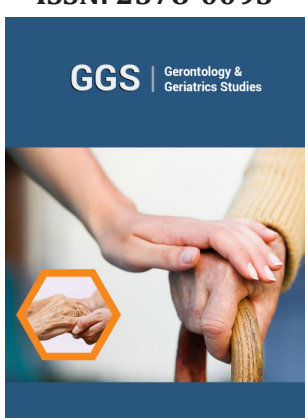

*Corresponding author: Mohammad Taghi Sheykhi, Professor of Sociology, Department of Social Science, Iran

Submission: 1 毕 June 18, 2018

Volume 4 - Issue 4

How to cite this article: Mohammad Taghi Sheykhi. Safety and Security Needs of the Aging People in Tehran, Iran. Gerontol \& Geriatric stud.4(4). GGS.000592.2019. DOI: $10.31031 /$ GGS.2019.04.000592

Copyright@ Mohammad Taghi Sheykhi, This article is distributed under the terms of the Creative Commons Attribution 4.0 International License, which permits unrestricted use and redistribution provided that the original author and source are credited.

\author{
Mohammad Taghi Sheykhi* \\ Department of Social Science, Iran
}

\begin{abstract}
The paper explores how various demographic and health factors have contributed to aging in Iran with particular attention to Tehran City wherein larger number of elderly people live. Iran's ageing increase was likely unexpected since the last 60 years when reforms and modernization gradually started especially in Tehran in terms of education, health, medication, sanitation, water improvements etc. Gerotologically speaking, all these variables affected aging in quantitative terms. What the aging population need is improvement in quality of life and response to the safety and security needs of these newly-emerging people. The economic and health conditions of the aging people are among the challenges which need to be prioritized and n responded not only in Iran, but in other developing countries too. Due to the old demographic structure, norms and values in Iran, and safety and security of the ageing people lag behind in many respects which need to be renewed. However, the hidden elderly poverty needs to be reduced, and the challenges to be transformed into opportunities for such increasing people.
\end{abstract}

Keywords: Demographic and health factors; Ageing increase; Quality of life; Safety and security; Poverty reduction

\section{Introduction}

In Iran, between 1956 and 2016, within 6 decades population aged 65 and over increased for as much as 542 percent, or annually about 9percent, that is: $\mathrm{r}=(4781488$ 7858670 ) $/ 758670 \times 100=542$ However, countries must first get rich and then get aged, but at the time being, some countries are getting and before becoming economically rich. Two countries such as Armenia and Georgia with GDP per capita income of $\$ 3500$ and $\$ 4000$, are having proportions of 11 percent and 14 percent aging population [1]. Therefore, many countries are currently facing challenges while they are not prepared for that. That is, means are not ready for the end.

Population ageing is an obvious outcome of the process of demographic transition. While the developed countries of the world have already experienced its consequences of ageing, the developing countries are facing them now. The present paper to reflects some of the dimensions of the elderly people's vulnerability in Tehran, Iran. While the recent emphasis on studies pertaining to the elderly in the developing world is mainly attributed to demographic transition, the deteriorating conditions of the elderly are results of the fast-eroding traditional family system in the wake of rapid modernization, migration and urbanization [2]. This has in turn caused the elderly in almost every society to face challenges and various forms of insecurity. In Iran too, conditions, such as isolation, loneliness, physical weakness, uncertain future, etc., contribute to the sufferings of the elderly people as a whole.

Abuse of the elderly or elder abuse was publicly acknowledged in 1980s. It takes many forms, from passive neglect to active torment, and includes verbal, emotional, financial and physical harm. As the proportion of elderly people rises, so does the incidence of abuse. Most older people get support and comfort from their families, but some people face exploitation and abuse. No single definition refers to abuse and neglect "any action or inaction by any person, which causes harm to the older or vulnerable person" [3]. Abuse against older person includes physical abuse, neglect (active or psychological Passive), institutional abuse, and domestic violence. However, most abuse against elder persons comes from family members. 
Some theorists say that abuse against older persons fits into a larger societal pattern of ageism and devaluation of older people [4].

As in other parts of the world, there has been an enormous growth in the elderly population in Iran also. Until the early 18th century, global population size was relatively static and the lives of the vast majority of people were "nasty and short". Since then, the size and structure of the global population have undergone extraordinary change. More than three decades have been added to life expectancy, with a further gain of one or two more decades commonly projected for this century [5]. If we look at the global ageing scenario, we would find that the population of the world, which was 5.7 billion in 1995, is expected to reach 10.8 billion by 2050 -a four-fold increase. In this fast-growing population, the percentage of the elderly will also increase rapidly-from 9.5 in 1995 to 20.7 in 2050. Further, amongst the elderly, the number of the oldest ones-those aged 80 and above-will increase more rapidlyfrom 320 million in 1995 to 1,050 million in 2050 [6].

So far as Iran is concerned, its elderly population (60-plus) has increased considerably during the last few decades. Their proportion in total population (about 70 million) has reached from 5.2 percent in 1976 to 6.6 percent in 1996. Today, nearly 4,500,000 elderly people live in Iran. According to Iran's national census, in 2016, about 8.5 percent of the total population of the country, and above 7.5 percent of Tehran's, was over 65 years of age. With regard to the current demographic structure, it is anticipated to have an unprecedented increasing trend of population ageing in the years to come-from 7.27 percent in 2006 to more than 16 percent in 2050 a phenomenon that has never happened before. Besides, since Tehran city has a good record of in-migration flow, the ratio of ageing population will be higher than the other urban areas in the coming years. It may also be pertinent to mention here that those born in early 1950s, at the outset of Iran's modernization process, are at present increasingly reaching ages 70 and over are usually much concerned about their economic security, safety, marginal participation, 1 and economic independence. This has also become a priority area for social welfare planning in Iran. As the Iranian society in general and Tehran city in particular are transforming, the characteristics of modern mega-cities are also appearing in them. Similarly, as the families are also transforming from traditional to modern, the living space is becoming very small and tight. In this process, the elderly face insecurity and other vulnerabilities. Besides, factors such as social, psychological, economic and cultural changes also influence the different dimensions of the lives of the elderly, including their social security, welfare, safety, social cares/ services, and ageism [2].

In this backdrop, the issues pertaining to ageing, elderly protection, residence quality, food conditions and their social networks are of prime importance. As a whole, the study intends to reflect an objective picture of the elderly people in Tehran. In this sociological appraisal, apart from studying the physical, material and emotional well-being of the ageing population, their sociocultural similarities and differences will also be appraised. The scenario, therefore, considers elderly's quality of life from a variety of perspectives, such as demographic foundations, social and family relations, economics, health and disability, etc. While the elderly with better economic conditions have more social security in their old age, the impoverished elderly largely face social insecurity.

Therefore, paying attention to the economic and social security of the elderly, particularly the women, with regard to their health and treatment services, is of prime importance in both urban and rural areas [7]. The present study aims at identifying the quality and quantity of different age-groups, including those moving towards the old age, which would help the social planners to be familiar with this hidden phenomenon that has not much been touched by any governing body so far. It is expected to improve the quality of life of these people from the perspectives made in this study. For the purpose of this research, in the 'elderly' age-groups people of $60 / 65$ years and of age are included. Such people usually have common characteristics [8].

The study would not only prove useful to students of gerontology, social sciences and welfare studies, but also help social workers, urban planners and others in the better understanding the quality of life of these people, their deficiencies, weaknesses and other dimensions of their vulnerability. It could also be a beginning for further studies in this field at national level. In the present paper, consequences of the change in the family as a unit, and in the living style of the elderly, their expectations, and relevant sociological theories will be analyzed. Besides, social policies necessary for the elderly will be discussed at length. Though policy makers and social researchers themselves, too, are prone to sufferings arising from old age, in this regard, they do not often project their own future and loneliness [9].

\section{Method of research}

The focus of the research is to present a combination of theoretic frameworks and empirical realties. For the empirical part of the study, 500 elderly people were randomly selected from different parts and neighborhoods of Tehran city. They were approached through direct interviews with the help of predesigned questionnaires. Eventually, the filled-in questionnaires were edited, electronically extracted and presented in the form of tables. The researcher also reviewed the background literature on ageing population from different societies of the world. In the theoretical part, the researcher tried to refer to, and make use of sociological and gerontological3 theories within reach.

\section{Findings}

Among the respondents, i.e., 500 elderly people, who were referred to, and surveyed in various parts of Tehran city on random basis, 89 (17.8\%) were in the age-group 60-62 and 99 (19.8\%) were in the age group 63-65. Gradually, and with increase in age, the ratio and number of ageing people finds a declining trend: In such a way, only six $(0.5 \%)$ people within the samples were found in the age-group 90 and above. The age structure further shows that the sex ratio for the elderly (i.e., 60 years and above) is 106 . This high sex ratio for the elderly is due to high fertility and high maternal mortality for the women in the past. The survey also 
found that the elderly with spouse were 60 percent, whereas the percentage of elderly widows was 29 , male elderly 8.4 percent, and finally those never married were 2.6 percent of the total elderly studied in various neighborhoods of Tehran. Similarly, 55.8 percent of the respondents enunciated that they never received any financial assistance from their sons, whereas 19.2 percent received a little bit.

Likewise, 18 percent declared that they were reliant on their sons' assistance, and finally 7 percent stated that they received a considerable amount of financial assistance from their sons every month. In Iranian culture, parents normally expect to be financially assisted by their sons in their old age. The above figures indicate that most of the elderly are facing financial constraints despite having male offspring. And, so far as the emotional attachment of the sons is concerned, almost 20 percent of the respondents said that they were highly attended by their sons, whereas 44.6 percent said that they were much benefited by the emotional supports of their sons, and 35.2 percent declared that they were not absolutely attended by their sons. The figure indicates that sons did not care for their elder parents at all. However, government support and help by social workers can to some extent reciprocate this lack. That is to say, due to such failure, social workers provide the elderly with the necessary assistance.

Results of the survey further show that financial support by daughters towards old parents is very insignificant. While a little less than two-thirds, i.e., 63.4 percent, of the respondents declared that they did not receive any financial help from their daughters, 20.4 percent asserted that they got it a little bit, and only 16.2 percent were satisfied with such help from their daughters. Such a scenario strengthens the idea of son preference in the Iranian society, and this heritage passes to the future generations too. However daughters emotionally attend to their old parents very much, as less than three-fourths, i.e., 73 percent, respondents gave an affirmative answer in this regard whereas only 27 percent replied in the negative. Generally speaking, such dissatisfactory helps and attentions from offspring to parents, particularly in the old age, and towards people who are highly traditional in their lifestyles and attitudes, create problems more due to emerging generation gap. Although literacy can help the elderly to get themselves engaged in reading books and newspapers, something like 27 percent of the respondents were not literate at all. This percentage was 16.7 for the male elderly and 37.8 for the female elderly. However, in the present study, about 20 percent of the male respondents had higher qualifications, while this ratio stood at only 1.6 percent for the female elderly. Among the samples studied at the neighborhood level, a large majority, i.e., 92.3 percent, declared that they get monthly pension, and the frequency of which is 97.6 percent for males and 87.6 percent for females. Besides, 8.8 percent have monthly incomes of about US\$ 55 , and about 23 percent have monthly income of more than US\$222. In other words, about 70 percent of the respondents used to live on incomes between US \$55 and 222 a month, which is very low at current costs of living.

The elderly usually have plenty of leisure time, and this is also reflected in the present study. While about 48.2 percent of the respondents preferred to watch television during their free time, 29 percent read books and newspapers, and the remaining 23 percent used other means of entertainment. Similarly, while the rate of reading newspapers by male samples as leisure is 22 percent, 55 percent of female samples assert that they watch television as their leisure. The results of the research show that little less than twothirds of the elderly, i.e., 64.6 percent, had mostly interrelations with their children, whereas 14.5 percent with their friends, 9.4 percent with relatives, and finally 11.5 percent with neighbors and others. While one of the psycho-spiritual needs of the elderly is known to be travel and tour, more than 20 percent of them had not traveled at all during the period of study. It is worth noting that the elderly in the Western countries usually travel very frequently.

Within the samples of the present study, the elderly were usually found satisfied with their access to medical services. To a question about their health and safety, only 39.3 percent of them declared that they were safe and healthy. Health demography 4 is very much associated with safety and security. On the other hand, 25 percent informed that they had arthritis problems, 10 percent of them had diabetes, and 27.4 percent had other ailments. In the course of inquiries, it was also found that 91 percent of the respondents were not at all interested in staying in nursing homes. Another variable indicates that 45 percent of the elderly people in our study are to some extent satisfied with their lives. This includes 40 percent* males and 50.2 percent* females.

\section{Discussion}

The basic concept of social security is not new to Iran. Traditionally, a sort of traditional support system (e.g., joint family system) existed before, to provide security to older destitutes and other vulnerable groups in society. In such circumstances, family was the protector of the elderly, and thereby, the elderly did not have to resort to the secondary institutions, such as nursing homes, for their protection. However, gradually, such system is disappearing, and state-based social security system has come into being, but it is not adequate for a large chunk of elderly population. Findings indicate that the offspring still feel responsible to help their elder parents as much as they can. For example, 18 percent of the respondents receive monthly financial help from their sons, and 7 percent assert to be fully assisted by their sons per month. Iran, which is comprised of 30 provinces and 1,015 towns and cities [10], does not have conditions of balanced development; in that, some provinces are more developed, than the others. Under such conditions, some of the elderly living in affluent provinces are in improved and better conditions, whereas others in deprived provinces need to be more attended and cared for. In the latter

${ }^{1}$ Exchange rate: US\$ 1 was equivalent to Rials 9,000 at the time of study.

*The rest to 100 percent is concerned with responses: much, very much and not at all 
provinces, they are in a state of more insecurity and vulnerability. For example, Tehran province, especially Tehran city, is reckoned as more secure site for the elderly. In Tehran, the elderly have more facilities with regard to public and private nursing homes, easier access to medicines etc. They have more and easy access to parks, hospitals and other places which can provide them with required services. Therefore, under such circumstances, men and women in other parts of the country like to migrate to this province, particularly Tehran, to be more benefited of care and security in their old age.

Similarly, as larger cities attract more social and material capital in Iran, they are more developed, and hence are provided with more facilities. Such perspectives attract more elderly people; often accompanied by their children. Because of young population structure in Iran, almost 60.74 percent of the entire population of the country stand at age groups 0-29 [11]. This young population is prioritized in different sectors of planning and housing investments. Thus, smaller investments on housing and health sectors are done in favor of the elderly. For instance, while a great number of the elderly people in various parts of the country are in immediate need of protection centers, they cannot easily have access to such facilities. They have to either live alone or be a burden on their offspring. Nevertheless, it is hoped that more priorities would be accorded to the elderly community in the fourth five-year plan scheduled to start in 2010. Based on inferences and ad hoc interviews with a number of elderly people, they do face many problems so far as their protection and care are concerned. However, the elderly with poor socio- economic backgrounds face multiple problems and constraints, for example, 8.8 percent of the respondents in Tehran with monthly incomes of US \$ 55 feel very poor to pay for their daily needs.

What is therefore required as an immediate step towards an improvement in the elderly's quality of life, is the establishment of centers for the elderly in all regions, which could meet their various needs, such as habitation, care and food. In the meantime, the negative attitudes of the people towards nursing homes must be changed in an acceptable manner, so that they could access improved social and economic lives. I must add that transformation of the economic structure of Tehran in the past few decadesfrom agricultural to industrial and service sectors; in the wake of urbanization, has, to a great extent, changed the attitudes of families towards the elderly members, and the quality of protection that they provide. They have now largely recognized nursing homes as a social fact and as a positive alternative to keep and protect the elderly. Younger family members being involved in modern civil life, they have implicitly come to recognize nursing homes as positive places to accommodate and attend the elderly. Increase in life expectancy rate in 2007 up to 71 years for males and 68 years for females in Iran (WPDS 2007), represents a good outlook of ageing in the country, which requires appropriate planning in both rural and urban areas. Based on table 1 in the present paper, life expectancy has highly contributed to the increase in percentage of the elderly between 1956 and 2006. Yet, increase in longevity is unjustly distributed among various social strata in Iran. However, such a transition contributes to rising needs of housing, pension, medical care, etc., within the growing elderly. Generally speaking, this scenario has caused the Iranian elderly people to gradually face the loss of inter-generational solidarity and integrity. Somehow or the other, results of the study confirm the emergence of the scenario. Based on the researchers conducted in different parts of Iran including Tehran, there are considerable differences in the quality of life within elderly males and females. Males are found to be in a comparatively better position. The differences stem mainly from more wealth within the, possibility of remarriage after losing spouse for males, more social respects for the male elderly etc. Such opportunities more await male ageing people rather than female ones.

\section{Theoretical concepts}

In the past, not only in Iran, but in many other societies also, the elderly were considered as sources of knowledge, rationality and experience. Currently, with the passage of time, and as a consequence of the social, economic and cultural changes taking place in all societies, they have gradually lost their importance and charismatic values. While in the 19th century, and even in the early 20th century, grandchildren rarely had the chance of seeing their grandparents, but now and particularly at the outset of the 21st century, with the rise in average age, three or more generations have got the opportunity to simultaneously live together.

Physical changes that spring up in people in course of time are not necessarily displayed among all people of the same age-groups in a similar manner, but their physical and mental effectiveness, and their reactions towards such factors, are different within different age-groups of elderly people. In fact, the elderly suffer one (in some cases, three at the same time) treatable sickness(s) [12].

From the demographic point of view too, the number of the ageing people in Iran is on increase, and the scenario needs the provision of more medical care, sufficient nutritious food, and other necessities of life. Under such conditions, special social policies should be made and applied for the elderly, and any failures in this regard would lead to problems for the elderly, and consequently they would reflect as a burden. In other words, though entering old age has been identified as ages 60-65, i.e., the age in which people usually get retired, yet, we cannot fix up a definite age border in which the people should be named 'aged' [13]. In another definition, old age has been called repeated dependency, i.e., a period followed by the period of dependency and socialization, followed by the second period, i.e., independence and maturity, and eventually the 'third age' or the beginning of the elderly period [14].

Census data indicate the sex ratio of 108 for those elderly people aged 80 and over [11]. Therefore, with regard to increasing female elderly, more arrangements should be made to protect them in their old age. Elderly women being poorer than men due to their limited sources of income in their old age, need to be more protected and attended. In a global comparison, in the developed world, while 18 percent of the people are aged 65 and above, the ratio stands at only 7 percent in the developing world [15]. In this regard, Iran's ratio 
of aging population stands at 73 percent, and that of Tehran stands at 6 percent [11]. On the other hand, while because of aging, there happens a sharp fall in people's safety, people's social costs, their medical and health costs increase too [16]. In this regard, creation of supportive establishments at neighborhood level would be very effective and enabling.

\section{Social isolation of the elderly}

One of the main dimensions of social insecurity and vulnerability of the elderly people stems from their social isolation. In fact, isolation is one of the general issues of old age and that is the result of the elderly's non-functionality or lack of role in the society. However, it is extremely difficult to measure or define social isolation [17]. It may be objective (e.g., social contacts can be counted), or it can be subjective (e.g., people can be asked about their feelings). Most studies on social isolation have been concerned primarily with the four types of isolation as outlined below:

A. By comparison with their contemporaries in the developed world: peer-contrasted isolation.

B. By comparison with younger people: generationcontrasted isolation.

C. By comparison with the social relationships and activities enjoyed by (other younger or middle-aged people): age-related isolation.

D. By comparison with the preceding generation of old people: preceding cohort isolation.

Measurement of isolation usually consists of information about social activities as a way of estimating the number of social contacts [18]. Quite a lot (one-fifth) of those interviewed in the present study were found isolated, or extremely isolated, and the majority of them included women (widowed). This high percentage of isolation within the elderly people is more due to the breakdown of joint family system, weakening of family network, and more migrations by the younger family members in Iran in current times as a whole. Isolation does not necessarily increase with age, but there is little variation in the likelihood of being visited by family, friends and relatives. The appearance of this phenomenon is highly due to the complexity of life in highly populated Tehran with poor and congested transportation network. Though the two concepts of isolation and loneliness are almost synonymous and are used interchangeably, yet, there is a conceptual distinction between the two. Isolation relates to circumstances (which can usually be measured, however crudely), whereas loneliness relates to feelings (often about these circumstances). Widows are also likely to experience loneliness as do others who have been bereaved [19].

The problems of isolation and loneliness not only arises within the elderly who are dispersed in a city, but they may also happen to the elderly residing in nursing homes. Studying the older people in residential care, [18] has commented that "the lack of even a single friend, a higher rate of severe or frequent loneliness, the discouragement of spontaneous social activity, the inability of visiting relatives and friends to adopt useful roles, the lack of satisfying, and sociable occupation (1986:38) - all represent isolation and loneliness by the elderly even in care centers." Social isolation is more problematic for women, since they usually live longer than their male counterparts. Culturally speaking, women usually have less outside-home relationships and contacts in Tehran as compared with men, and as a whole in Iran, and that contributes to more likelihood of isolation among them. Similarly, as mentioned earlier, women in Tehran City have longer life expectancy than men in this city. Such a phenomenon makes them highly vulnerable in various grounds and spheres. Under such conditions, women are more prone to psychological sufferings like dementia. While sociologists highly recommend that the elderly should have their own independent lives yet providing them with adequate financial resources remains unsolved in many instances. Clinicians have identified a broad array of risk factors typically associated with elder abuse and neglect [20]. Factors such as caregiver's mental health, substance abuse, dependence on the care recipient etc., have been described as important indicators leading to social isolation of the elderly. Similarly, widowhood, the deaths of friends or children moving away can lead to social isolation [21]. Such circumstances widely relate to Tehran City too. To get rid of the problem of isolation among the elderly, social networks can be proved very important. These networks may include both the fellow co-residents as well as from beyond the household, including friends, neighbors, etc. So far as the elderly in Tehran City are concerned, there are still further steps to be taken in their favor. For example, friendship centers are to be established in neighborhoods to help them with isolation.

\section{The elderly's housing}

Adequate and suitable housing is also reckoned as an example of the elderly security, and the provision of which would bring safety and security to the weak and disabled elderly. However, there is a growing recognition of the link between poor heath and housing. Features such as the absence of stairs/ramps may force even a very frail person to continue living independently. Many old people, however, live in less than desirable housing and some of them have particular problems. There is evidence, too, that some people remain in residential care only because alternative accommodation is lacking [22,23]. In the course of interviews with the senior respondents in Tehran City, the researcher came to know that almost 60 percent of the interviewees preferred/wanted neighbors without children. The study found that such housing sites give older people more feelings of well-being - giving them more control over their social contacts.

Though the problem of elderly's adequate and suitable housing has to some extent been tackled in the Western societies, it still does exist in the developing nations, including Iran. If we look at the basic family structure in Tehran, many parents are found to live with their children, as a joint families. Therefore, the elderly's housing quality tends to depend on the economic capacity and shelter patterns of the household. It is worth noting that the trend in population aging (growth) in Iran is even faster than its socio-economic growth rate. Thus, if necessary, arrangements are not made for the elderly in a futuristic manner, the gap/difference will contribute to further 
challenges for the elderly. In view of this, dealing with this problem in urban areas has been a priority for the large city of Tehran. So far as preferences in apartment living is concerned, no single type of housing fits all older people in Tehran. But older people do prefer some types of apartments and neighborhoods over others; depending on their middle-age lives and backgrounds. The main question or hypothesis in this research is to find out how far more social security plays a vital role in lowering elderly's vulnerability in different dimensions.

\section{Types of insecurity}

Although there has been a rise in the all-age mortality from accidents, the number of deaths from accidents in those aged 65 and above is fairly constant. In the course of study, the researcher came to know that the elderly are frequently at risks at different conditions.

a) Older people, like people of other age-groups, suffer domestic accidents, fires, burns, poisoning, road/workplace accidents and falls.

b) Older people are at particular risk from injury or death from domestic fires.

c) Falls account for almost one-third of deaths from all accidents. Older people are at particular risk with 65 percent of fatal falls occurring among those aged above 75 .

\section{Risks factors and recommended strategies}

The risks factors that the researcher acknowledged associated with accidents and injuries among old people are very broad and include the following:
a) Environmental factors
b) Inappropriate use of medicine
c) Poor health status
d) Disability
e) Being overweight
f) Lack of exercise
g) Nutritional deficiency
h) Poor housing
i) Lack of training for careers

However, as the number and proportion of the elderly in Iran is growing; especially those living alone, they may be more vulnerable to accidents. Therefore, greater attention should be paid to their safety and security both inside and outside home. Thus, a number of strategies aimed at these people should be implemented:

a) Extended awareness programs for older people, their careers and health professionals associated with accidents.

b) Promotion of healthy aging practices, such as reduced smoking, increased exercise etc. c) Educational programs to improve knowledge and safety skills.

\section{Conclusion}

In this research, a multidimensional perspective of the elderly's life in the capital city of Tehran, as part of the macro society of Iran, is presented. The research reflects that the 'new elderly' (those born in early 1940s) have even more concerns as compared with the 'older elderly', or a generation before them. Tehran, being a migrant-receiving city, while the ratio of its in- migrants is higher than other cities, the expectations of the elderly in this city are by far different from those in other cities. Under the conditions of modern life, elderly's general welfare, care/protection and financial constraints are quite remarkable in different neighborhoods with special reference to the current socio-economic conditions. Tehran City is considered as a part of the country wherein the elderly is more prosperous. They have easier access to medical care, nursing homes etc. Based on researches done in various age-groups, marked variations have been found with regard to the quality of life of male and female elderly people; stemming from more wealth within the reach of males, possibility of remarriage by the male elderly and so on. While the improved socio-economic conditions have made it possible for three generations to live together, yet, modern life has also forced them to live away from their families. Regardless of class, race, creed and color among the elderly, what is common among them, is disability and dementia. While this research has considered and analyzed some of the challenges, profiles and problems of the elderly, yet, the scenario of aging needs more research studies on a regular basis in the future too.

\section{Notes}

Marginal participation: Today, industrial societies often consign older people to marginal participation in the economy because they lack the knowledge and training demanded by a fast-changing marketplace. Such an idea is currently extending to newlyindustrializing societies too. The elderly gets the jobs that involve minimal activity.

Ageism: The concept is used to justify the social disadvantage of minorities. It is used paralleled with racism, sexism etc. Sociologists use the term to designate prejudice and discrimination against the elderly. Ageism could be reflected for example as when individuals deny elderly women or men a job because of their age. Or, when people subtly speak to the elderly as if they were children.

Gerontology: The scientific study of ageing and the elderly focuses on biological and psychological changes in old age, as well as cultural definitions of ageing. It was dominated in the 1960s by the welfare needs of the elderly within social policy framework. It is concerned with age, the politics of ageing, the experience of ageing, and in the idea of aging as a normal process.

Health demography: This topic has long been an impetus for the development of demographic analysis and methods, and an important area with the analysis of morality. But, interest in the concept has increased noticeably as the population of the world 
diversifies and grows older. It examines deaths and injuries with especial reference to the elderly.

\section{References}

1. (2017) ESCAP, UN population copyright, Addressing the challenges of population ageing in Asia and the Pacific.

2. Irudaya Rajan S, Sankara Sarma P, Mishra US (2005) Demography of Indian aging, 2001-2051 In: Phoebe S, Kiebig \& Irudaya Rajan (eds.), An Aging India: Perspectives, Prospects and Policies, Rawat, Jaipur, India.

3. 2002 Council against abuse of older persons, Abuse and neglect of an older or vulnerable person. Laminated handout. Sponsored by St Joseph's Health Care, and McMaster Centre for Gerontological studies, Hamilton, ON: Promark Printing.

4. Harbison J (1992) Changing career of elder abuse and neglect as a social problem in Canada: Learning from feminist frameworks. Journal of Elder Abuse and Neglect 11(4): 59-80.

5. David BE, David C (2008) Population ageing, Human capital accumulation and productivity growth: Population council publications, New York, USA.

6. (1998) United Nations, World Population Projections to 2150.

7. (1999) UNFPA, Key Actions for the future implementation of the programme of action of the international conference on population and development (ICPD), General Assembly, New York, USA.

8. Turner BS, Abercrombie N, Hill S (2000) Penguin dictionary of sociology: The Penguin Books, London, UK.

9. Shamloo Q (1985) What is old age? Why we grow old? $1^{\text {st }}$ ed: Sherkate sahamie chehr publications, Tehran, Iran.
10. (2005) Statistical year book of Iran, Tehran: Statistical Centre of Iran Publications.

11. (2006) Population and housing census of Iran: Statistical Centre of Iran Publications, Tehran, Iran.

12. Keddie K (1978) Action with the elderly: Pergman, London, UK.

13. Akbarzadeh N (1997) Passing from adolescence to old age: Al-Zahra University Publications, Tehran, Iran.

14. Laslett P (1998) A fresh map of life: The emergence of the third age: Weidenfeld \& Nicolson, London, UK.

15. (2017) World population data sheet, PRB, Washington DC, USA.

16. IFA (2001) The Journal of the international federation on ageing, Summer, Montreal: Taylor \& Francis.

17. Shanas E (1968) Old people in three industrial societies: Routledge, London, UK.

18. Townsend P (1968) Ageism and social policy: Gower, London, UK.

19. Bury M, Holme A (1991) Life after ninety: Routledge, London, UK.

20. Podneiks E (2004) Social exclusion: A risk factor for elder abuse, Gerontologist 44: 849-857.

21. Hall M, Havens B (2002) Social isolation and social loneliness, In writing in gerontology: Mental health and ageing 18: 33-44.

22. (1988) Wagner, Report, Residential Care: Positive Choice: HMSO, London, UK.

23. Documents of population and housing censuses 1956-2006: Statistical center of Iran publications, Tehran, Iran. 